\title{
Relationships in the Sex Hormone Groups
}

\author{
By Prof. L. Ruzicka, Technische Hochschule, Ziirich
}

$\mathrm{T}$ HE sex hormones may be divided into two main classes. One class comprises the gonadotropic hormones, the chemical structure of which is still unknown, and which stimulate the gonads to the production of the real sex hormones. It is possible that the gonadotropic hormones are identical in both sexes. However, the occurrence of the real male and female hormones, which form the subject of this article, is also not specific for the sexes, since it has been proved by their action that hormones of the other sex can exist in the male as well as in the female organism. A female hormone has been successfully isolated in a pure state even from the urine of stallions ${ }^{1}$. The specific action of the male and female hormones is confined only to the development and maintenance of the functions of the sex organs and glands and the secondary characteristics of the sex under consideration. This, however, by no means excludes the possibility that both groups of hormones can play a definite biological part in both sexes. Lately, a substance, androstene-3,17-diol, was prepared artificially ${ }^{11}$, which showed even male and female hormone activities ${ }^{2}$.

The sex hormones afford one of the best examples of how Nature, in using a fundamental principle, can produce not only different but even contrary actions by an alteration in the details of this fundamental principle. The common characteristic of all sex hormones is that they can be derived from cholesterol (I) by splitting off a part of the side-chains, and thus they all contain a ring system consisting of four carbon rings. The difference between the individual hormones depends upon which part of the side-chains has been split off, and is, moreover, essentially due to the variation in hydrogen content.

On account of their schematic structure, the work of determining the constitution of the sex hormones has been very considerably facilitated. Once the empirical formula has been determined and the groups present in the molecule identified, the correct molecular structure of a newly isolated hormone could be guessed by considering how such a compound could be most simply derived from cholesterol. It will be of interest to trace briefly these relationships in the individual groups of sex hormones ${ }^{3}$.

The œstrane group (VII-XI) comprises the female sex hormones, with the exception of progesterone (II), and is characterised by the presence of

18 carbon atoms in the molecule. One of the most important points in the elucidation of the con. stitution of this group was the conversion into a phenolic dicarboxylic acid, and from this it could be supposed that the hydroxylated ring in œstrone (VII) is a benzene ring, the presence of which also affords an explanation for the splitting of one methyl group from cholesterol in the forma. tion of this hormone group. Estradiol (Ix) could be obtained by reduction from œstrone, and cstriol (XI) may be transformed into œstrone by the removal of water. Formula (x) for equilenin is the simplest expression for a naphthol derivative in this group, and except for the position of the fourth double bond, the con. stitution of equilin (VIII) is established. In addition, all the details of the structure of the cestrane group are established by chemical reactions ${ }^{4}$ and only the steric structure remains in doubt, although this is very probably identical with that of cholesterol.

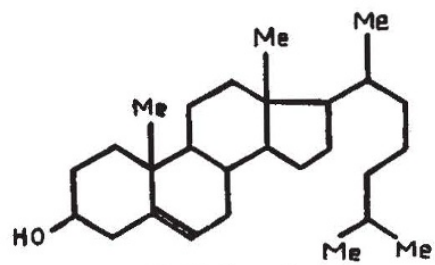

(I) Cholesterol.

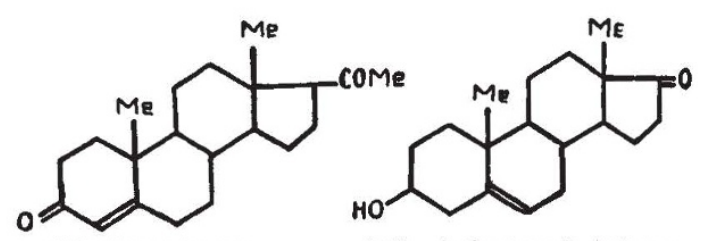

(II) Progesterone.

(III) Androstenc-3-ol-17-one.

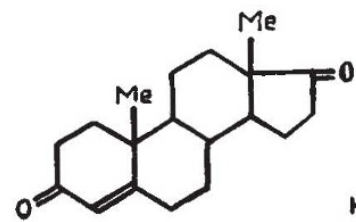

(IV) Androstene-3, 17-dione.

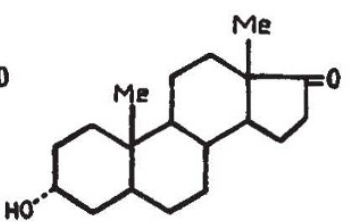

(V) Androsterone.

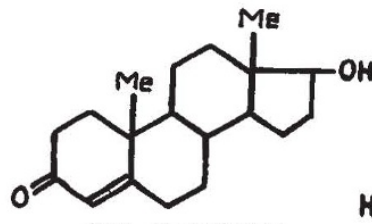

(VI) Testosterone.

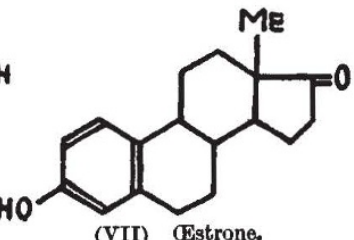




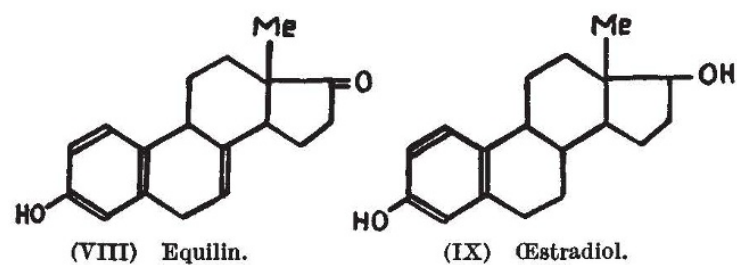

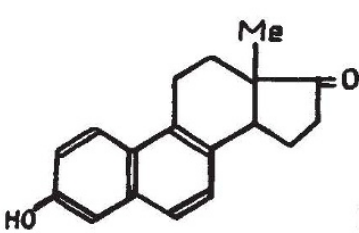

(X) Equilenin.

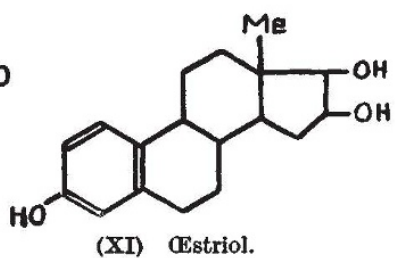

(XI) Estriol.
The fact that progesterone is an unsaturated diketone with the empirical formula $\mathrm{C}_{21} \mathrm{H}_{30} \mathrm{O}_{2}$ led to the proposal of formula (II), which could be verified by an artificial preparation of progesterone which had stigmasterol as its starting materials.

A similar relationship was found to exist in the first two male sex hormones, which were isolated by $A$. Butenandt in a pure state from urine, and are characterised by the presence of 19 carbon atoms. From the empirical formula of androsterone it was supposed that it is related to a hydrogenated sterol. The details of the structure of this hormone (v) were definitely settled by its artificial production from epicholestanol. The similar preparation from cholesterol of the other male hormone present in urine showed it to be androstene3-ol-17-one (III) ${ }^{5}$.

The ready accessibility of androsterone rendered possible thorough physiological investigations $s^{\mathbf{b}}$, which soon proved that androsterone could not be identical with the male hormone from testes. In the first place, the highly purified testicular extract was considerably superior to androsterone in its action on the sexual glands of castrated rats $^{7}$; secondly, definite chemical properties of the active substance from testes pointed to a different molecular structure from that of androsterone. The physiological action of the testicular extract was destroyed by alkali and by potassium permanganate $^{7}$ under the very conditions which left androsterone unattacked. This fact led to the correct view as to the structure of the testicular hormone even before the hormone itself had been isolated in a pure states. The instability towards alkalis was the chief reason for our view that an $\alpha, \beta$-unsaturated ketonic group is present in the testicular hormone, since such compounds are, as a rule, less stable towards alkalis than the corresponding saturated ketones. In the androstane group, the simplest $\alpha, \beta$-unsaturated ketonic compounds which can be derived from cholesterol are androstene-3, 17-dione (IV), and androstene-3one-17-ol (vI), and accordingly these suggest them- selves as possible formulæ for the testicular hormone.

The first test of this hypothesis was made possible by the physiological examination ${ }^{9}$ of the androstene-dione prepared from cholesterol. The properties of this diketone corresponded, although not completely, yet in essential features with those of testicular extract, and therefore as a further test it was necessary to carry out the artificial preparation of compound (VI). At this point our synthetic method for the elucidation of the testicular hormone happened to coincide with the analytical method of Laqueur and his coworkers. These workers had meanwhile succeeded in isolating the pure hormone from testes ${ }^{10}$; it was named testosterone, and was different from our diketone (Iv). The similarity in physiological action between the diketone and testosterone, however, afforded a means of testing whether the second of the two formulæ proposed for the testicular hormone, that of androstene-3-on17-ol, should not be given consideration. Indeed, testosterone yielded androstene-dione on oxidation $^{11}$ and the androstene-3-one-17-ol prepared from cholesterol by suitable methods was identical in all its properties with natural testosterone ${ }^{12}$. This hormone is about 20-25 times more powerful than androsterone in its action on the sexual glands, for example, the seminal vesicles, the prostate and Cowper's glands : its male hormone action exceeds that of any compound as yet isolated from an organism.

However, in spite of this, the whole problem of the male hormone action of testicular extract is not yet completely solved, since according to Laqueur and his co-worker ${ }^{10}$ testicular extract contains as well as the hormone a constituentthe so-called $X$ substance-which is by itself inactive but the presence of which markedly increases the characteristic action of testosterone.

The recognition of the fact that $\alpha, \beta$-unsaturated ketonic compounds are responsible for male hormone action offers a plausible explanation for the origin from cholesterol of the sexual hormones of the cestrane and androstane groups present in organisms. Androstene-3, 17-dione may be assumed to act as an intermediate product ${ }^{5}$, although it has not yet been detected in Nature, as by hydrogenation of the double bond and one ketonic group it could be converted into androsterone ; in this way it also provides an explanation for the epi-position of the hydroxyl group in the latter. Moreover, œstrone might be produced by the removal of methane from androstene-dione. In the same manner œstradiol, the most powerful female hormone which was isolated by E. A. Doisy from the ovary, could be derived from testosterone, the most powerful male hormone. Finally, the testo- 
sterone in organisms might also have its origin in a partial hydrogenation of androstene-dione. Thus a possible explanation is obtained for the simultaneous occurrence of the male and female hormones in one organism.

The appearance of different hormones with similar action in organisms leads to the question of the relationship between their constitution and physiological action, and, furthermore, to the question of the chemical specificity of hormone action. The specificity is most evident in progesterone, which as yet is the only compound possessing the complete characteristic corpus luteum hormone action. The specificity of the hormones in the cestrane group (VII-XI) is no doubt considerably smaller, as they all show approximately the same qualitative action, the main point of difference being merely a quantitative one. In all the hormones of the cestrane group the phenolic ring is present unchanged, whereas in contrast, this ring in the androstane group (III-VI) is variable, and this group of hormones is accordingly characterised by the largest number of compounds which, in spite of differences in chemical structure, yet show very similar physiological action.

The formulæ (III-VI) give only a partial indication of the possible variations in the androstane group. We have recently discussed ${ }^{13}$ more than twenty physiologically active androstane derivatives in which relationships between constitution and action can be undoubtedly recognised. These investigations involved the preparation of the 17-methyl-testosterone, which according to preliminary results seems to show an activity on the sex glands of castrated rats slightly higher even than that of testosterone. In different laboratories and medical research institutes, the most powerful of these compounds, especially testosterone, have been subjected to a thorough investigation, which should provide the answer to the question as to range of the physiological action of the male hormones in healthy and diseased organisms.

\footnotetext{
B. Zondek, NATure, 133, 209, $494 ; 1934$.

E. Tschopp, Praxis, Schweiz. Rundschau für Medizin, December 12, 1935, and Arch. internat. Pharmacodyn. et Therapie, January, 1936. $758 ; 1934$.

' Cf. the latest paper in this field by A. Cohen, J. W. Cook and C. L. Hewett, J. Chem. Soc., 445; 1935 .

R. V. Ruzicka and A. Wettstein, Helv. Chim. Acta, 18, 986 ; 1935. R. Oppenauer, NATURE, 135,$1039 ; 1935$. W. Schoeller, A. Only the latest papers are mentioned. 1935.

Callow and $\mathbf{R}$. Deanesly, Biochem. $J$., 29, $1424 ; 1935$. Lancet, ii, 77; 1935. A. Parkes, Chem and Ind, 928; 1935. V. Korenchevsky, M. Dennison and S. L Simpson, Biochem, $J$ 2131; 1935. V. Korenchevst and S. L. Simpson, Biochem. J., 29, 2131; 1935. V. Korenchevsky, internat. Pharmacodyn. Therapie.

Freud and E. Laqueur, NATURE, 125 $184 ; 1935$.

${ }^{8}$ E. Laqueur, P. de Fremery, J. Freud, S. E. de Jongh, S. Kober A. Luchs and A. P. Münch, Berichte über die gesammte Physiologie, 6 1931. T. F. Gallagher and F. C. Koch, Endocrinology, 18, 107; 1934. Matsuzaki Kwanji, Jap. J. Med. Sci., 7, 1515; 1934.

E. Tschopp, NATURE, 136, 258; 1935.

${ }^{10} \mathrm{~K}$. David, E. Dingemanse, J. Freud and E. Laqueur, Z. physiolog. Chem., 233, $281 ; 1935$.

11 K. David, Acta brev. Neérland., 5, 85, 108 ; 1935

${ }^{19} \mathrm{~L}$. Ruzicka and A. Wettstein, Helv. Chim. Acta, 18, $1264 ; 1935$. A. Butenandt and G. Hanisch, Ber. Deutsch. Chem. Ges., 68, 1859 ; 1935 .

${ }_{13}$ L. Ruzicka, M. W. Goldberg and H. R. Rosenberg, Helv. Chim. Acta, 18,$1487 ; 1935$.
}

\section{Obituary}

\section{Dr. R. G. Canti}

$\mathrm{B}^{\mathrm{x}}$ $Y$ the death of Dr. Ronald George Canti on January 8 at the early age of fifty-two years, the medical profession loses not only a distinguished consulting pathologist but also a brilliant experimental investigator.

Borm in 1883, Canti was educated at Charterhouse, King's College, Cambridge, and St. Bartholomew's Hospital, London. After graduating in medicine he became house physician to the late Dr. Samuel West, and in 1915 joined the teaching staff of St. Bartholomew's Hospital as a demonstrator of pathology. $\mathrm{He}_{\Theta}$ remained a member of the Pathological Department until his death, being successively senior demonstrator of pathology, bacteriologist to the hospital, and ultimately clinical pathologist and medical officer of health to the hospital. In addition to his hospital work, he carried on a large private consulting practice as a pathologist. In all matters relating to his profession he was an acknowledged master. The late Sir Frederick Andrewes, whose senior assistant he had been for many years, was wont to declare that Canti was the finest clinical pathologist he had ever known.
The heavy demands of private practice, and the routine work connected with his hospital appointments, would have taxed the energies of any ordinary person. But Canti was no ordinary person. He was indefatigable. His quick intelligence, vivid imagina. tion, wide knowledge and superlative technical skill, were always at the disposal of his colleagues and friends, and continually being used by them.

Canti's chief claim to public recognition, however, is the brilliant scientific work which he carried out during the past dozen years on the development of normal and malignant cells and their response to radiation. Active participation in the intensive clinical research on the effects of $X$ - and radium rays on cancer, which was carried out by the staff of St. Bartholomew's Hospital immediately after the close of the Great War, convinced him that progress was greatly retarded by the prevailing ignorance of the fundamental action of these agents on living cells.

Further consideration led Canti and one or two other Bart's men to recognise that the late Dr. T. S. P. Strangeways had so perfected the art of cultivating living tissues in vitro as to afford an 